\title{
Evaluation and Improvement of Multiple-choice Questions in the Doctor of Pharmacy Program
}

\author{
Abdulkareem M Albekairy ${ }^{1,2}$, Nabil Khalidi ${ }^{1,3}$, Wesam W Ismail ${ }^{1 *}$, \\ Rami T Bustami ${ }^{1}$, Esra'a I Khader ${ }^{1}$, Abdulmalik M Alkatheri ${ }^{1}$ and \\ Amjad M Qandil ${ }^{1}$ \\ ${ }^{1}$ College of Pharmacy, King Saud Bin Abdul-Aziz University for Health Sciences \\ (KSAU-HS), Ministry of National Guard Health Affairs, Riyadh, Kingdom of Saudi \\ Arabia \\ ${ }^{2}$ King Abdulaziz Medical City, Ministry of National Guard Health Affairs, Riyadh, \\ Kingdom of Saudi Arabia \\ ${ }^{3}$ College of Pharmacy, University of Michigan, Ann Arbor, Michigan, USA
}

*Corresponding Author: Wesam W Ismail, College of Pharmacy, King Saud Bin

Abdul-Aziz University for Health Sciences (KSAU-HS), Ministry of National Guard

Health Affairs, Riyadh, Kingdom of Saudi Arabia.

\author{
Received: September 22, 2020 \\ Published: November 07, 2020 \\ (C) All rights are reserved by Wesam $\mathbf{W}$ \\ Ismail., et al.
}

\begin{abstract}
Objectives: To evaluate the quality of the current multiple choice questions (MCQ) in our bank, and to review the appropriateness of the student assessment processes by faculty in this Doctor of Pharmacy program. Also to identify barriers to the reduction of item writing flaws (IWF).

Methods: Faculty, in teams of two, reviewed 7620 MCQs of the question bank. Two more follow up reviews were then performed to further understand the reasons behind the MCQ IWF: (1) 2185 randomly selected MCQ were monitored for timely submission (which is one week before the exam), and (2) the deleted MCQ post exam administration among the randomly selected 2875 MCQ. In both projects, the level of cognition was also investigated.

Results: IWF in 7620 were conservatively assessed at 29.5\%. IWF increased as the number of instructors in a given course increased. Late submission of questions in the studied sample of 2185 MCQs was at 22\%. That has gotten worse as the years progressed year 1 to year 3 implicating pharmacy practice joint faculty more than others. MCQ deletion from the 2875 random sample was $4.6 \%$ across all levels of cognition. Negative correlation was found between the number of teaching faculty and percent of flawless MCQs.

Discussion: To reduce IWF, all processes of assessment must be monitored, and appropriate interventions instituted through education to faculty, review of MCQs prior to processing, engaging faculty in the improvement process. Full time college-based dedicated faculty tends to create an environment of cooperation between all faculty which in turn reduces weaknesses in the assessment processes.
\end{abstract}

Keywords: Item-writing Flaw; MCQs; Quality Improvement; Pharm.D.; Education

\section{Introduction}

Student assessment is an essential part of academic teaching. It reveals the quality and quantity of knowledge that was gained by the examinees throughout the course of instruction and determines if the student passed the course based on a preset standard of performance [1]. Most health science institutions use multiple 
choice questions (MCQs) as a conduit to making such an assessment along with other tools of assessment. Writing such questions can be a challenging task as each needs to be crafted clearly, and be flaw-free in order to maximize the accuracy of assessment and to minimize the influence of MCQ anomalies on adversely affecting the examinees performance especially the highly achieving ones $[1,2]$. The psychometric analysis of any MCQ through the calculated difficulty index and point bi-serial correlation, in addition to the faculty's expert judgment, are tools that can assist in pointing to difficult or poorly crafted MCQ [2-4].

The Quality Assurance and Academic Accreditation (QAAA) unit members of the College of Pharmacy (COP) at King Saud bin AbdulAziz University for Health Sciences (KSAU-HS), Riyadh expressed concerns over what they believed the questionable appropriateness of some MCQs in our assessment unit bank of questions. This concern was expressed in a focus group discussion where it has been proposed to initiate a focused review of MCQs to improve their respective quality. The review included checking the MCQs item's structure, grammar, spelling, phrasing, punctuation, language and logic. In addition to the specific purpose of this project which was to correct, improve, or eliminate inappropriate MCQs; lay down ground rules to improve student performance in exams; assist the students in focusing their attention the topics the MCQ is assessing rather than having them distracted by the level of language used or the content of poor MCQs; and most importantly to improve faculty's performance in writing MCQs.

\section{Methods}

Retrospective review of MCQs in the bank for appropriateness

A comprehensive review of 7,620 MCQs for 23 pharmacy courses (9 Pharmaceutical Sciences (PHBS 27 Credits) and 14 Pharmacy Practice (PHCS 39 Credits) taught in the first three professional years was performed by the teaching faculty at COP- KSAU-HS.

Fifteen courses were not included in this review since students' assessment is driven by rubrics rather than by MCQ exams (3 research and seminar courses, and 5 introductory and 8 advanced pharmacy practice experiences). All faculty reviewers were graduates of the North American and British educational systems.

The retrospective review process was planned for the 20142015 academic year. However, given the large number of reviewed MCQs by faculty teams of two, and due to their respective daily academic duties, it was not concluded until January 2016. All review- ers received a standard set of instructions prior to commencing the MCQs vetting, reviewed required college based writing criteria for MCQs, and agreed to a uniform MCQ evaluation process in order to improve the consistency in judging the questions and to eliminate bias. The criteria evolved around MCQs spelling and grammar, phrasing, structure, and content. The data were then tabulated as passed; corrected; rejected; or duplicated.

At the conclusion of this review and with the generation of preliminary results, it was decided to expand the project to retrospectively document what the likely factors that influenced the quality of written MCQs and to what extent to determine if interdependencies existed. The identified factors were the number of late submission of MCQs by faculty, the number of cancelled MCQs after the students attempted them in exam, and the students' evaluation of courses.

\section{Retrospective review of late submission of MCQs}

2185 MCQs covering 437 lectures from 14 courses taught in Academic Year 2015/2016 were selected at random. Dates of MCQ submission were logged down relative to the date of the examination. Course-specific data on professional year, department, number of teaching faculty, and number of lectures were also gathered and analyzed.

Retrospective review of cancelled MCQs in attempted exams and their level of cognition

A comprehensive review was performed for 2875 exam multiple choice questions (MCQs) for 30 pharmacy courses that were taught in 2016-2017 to assess the percentage of MCQs cancellation, their level of cognition, and the documented rationale for cancellation by course coordinators.

\section{Student evaluation of courses}

Students' evaluation of 43 courses taught in the academic years 2015-2016, and 2016-2017 were reviewed for investigating possible trend or correlation between students' perception of courses and adverse findings of wrong, late, and MCQ that had to be cancelled.

\section{Statistical analysis}

Descriptive statistical analyses were performed after classifying the study sample. The MCQ writing faculty were further categorized as Pharmacy Practice faculty who are college based or joint faculty who are hospital based clinical pharmacists, or Pharma- 
ceutical Sciences faculty, and lastly all faculty in the two academic departments. Comparisons were made using the Chi-square test. Number of teaching faculty was expressed as mean (SD) and analyzed using the t-test. The Pearson correlation was used to quantify the relationship between number of teaching faculty and percent of MCQs passing the review. Statistical significance was considered at $\mathrm{p}<0.05$. All statistical analyses were performed using SPSS 21.0 [Release 21.0.0.0, IBM, USA].

\section{Results}

A total of 7620 MCQs were reviewed. Overall, 70.5\% of the reviewed MCQs passed the review without changes. The vast majority of the remaining MCQs were corrected for language (12.4\%), Structure $(9.1 \%)$ or for both language and structure issues $(2.3 \%)$. Only $3.7 \%$ were rejected for content issues and $2.0 \%$ were rejected for exact duplication. Pharmaceutical Sciences courses had a significantly higher percentage of MCQs that passed the review (71.6\%) than those in Pharmacy Practice (68.9\%); $p=0.011$. Results by department and teaching faculty type are shown in figure 1. Joint clinical faculty in pharmacy practice (hospital based) had 66\% successful MCQs whereas full time clinical faculty in the same discipline had $72 \%(\mathrm{p}<0.002)$. When the number between the teaching faculty per course was correlated with the percentage of MCQs that passed the review, a non-significant negative relationship was demonstrated [Pearson correlation ( $\mathrm{r}$ ) $=-0.34, \mathrm{p}=0.12$ ] (Figure 2). This signals a trend toward lower quality of MCQs with increased number of teaching faculty. It was, however, significantly higher in courses taught by joint faculty (6.8) vs. full time faculty (2.9) (p = 0.001). [Pearson correlation $(r)=-0.61, p=0.048$ ] (Figure 3 ).

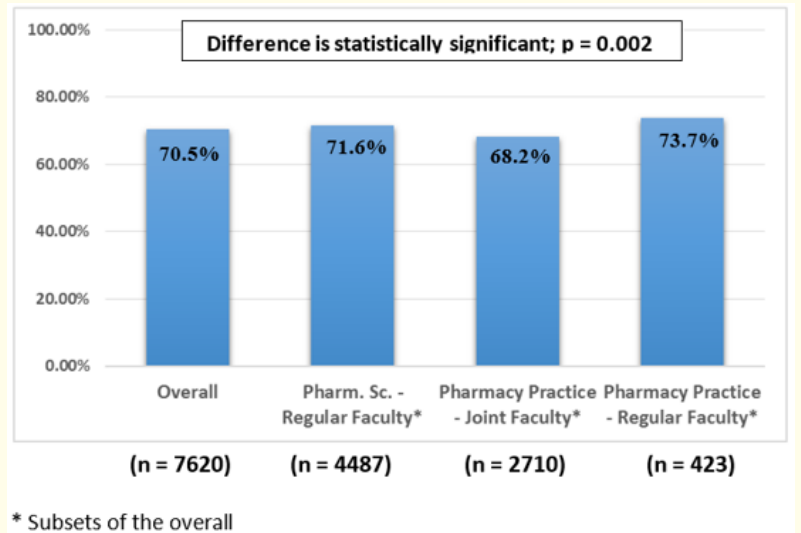

Figure 1: Percentage of MCQs that passed the review with no changes by course group. Total number of MCQs reviewed =7,620.

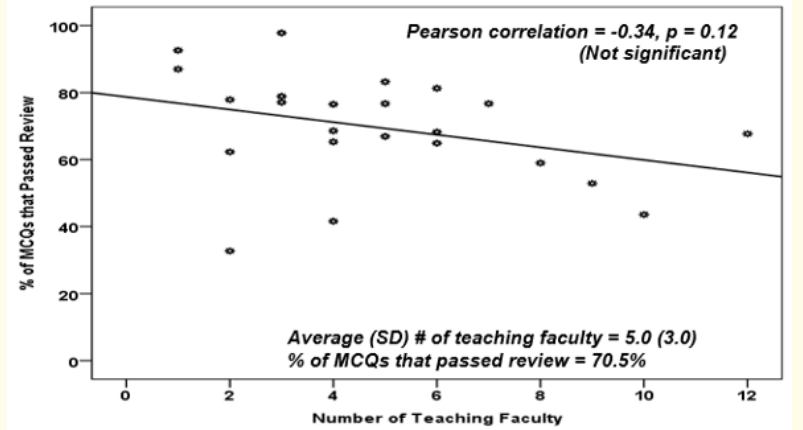

Figure 2: Correlation between number of teaching faculty per course and \% of MCQs that passed review, with regression line. Total number of MCQs $=7620$.
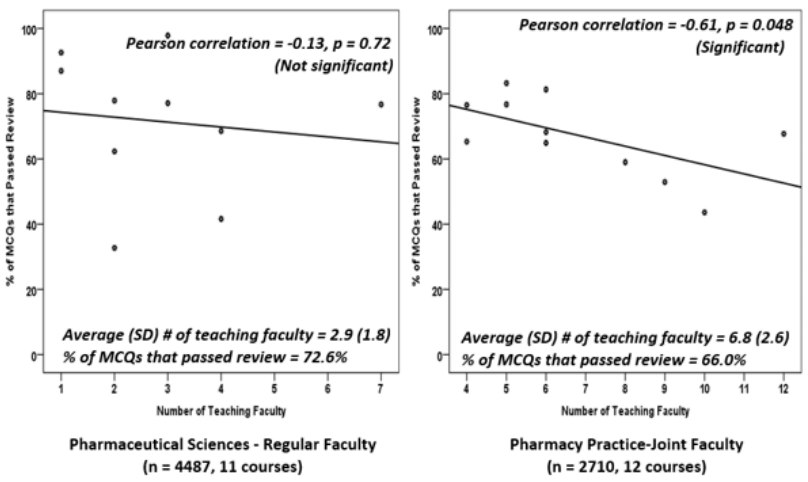

Figure 3: Pharmacy Courses: Average Number of Teaching Faculty per Course with $95 \%$ CI by course group. Number of MCQs $=7197$.

For the late submitted MCQs, of the 2185 MCQs covering 437 lectures in 2015-2016, only 1680 MCQs were received within seven or more days prior to the exam. About 500 MCQs (22\%) were delinquent within a range of less than a week up to one day before the exam. This represented 5 of the 13 monitored courses. All five courses were ranked below average in MCQ accuracy. The median time was significantly different by year and department (Table 2). The median (IQR) time in days was 13 (7 - 28); 18.5 (9 - 31) in professional year 1 courses, 8 (5 - 18) in professional year 2 courses and 11 ( 6 - 39) in professional year 3 courses; $p<0.001$. The results by department was 17 (7 - 31) days for pharmaceutical sciences courses vs. 11 (6.8 - 27) for pharmacy practice courses; $p=$ 0.018 . 


\begin{tabular}{|l|c|c|c|c|c|}
\hline Passed & \multicolumn{3}{|c|}{ Corrected } & \multicolumn{2}{c|}{ Rejected } \\
\hline No Changes & $\begin{array}{c}\text { Corrected } \\
\text { Linguistic }\end{array}$ & $\begin{array}{c}\text { Corrected } \\
\text { Structure }\end{array}$ & $\begin{array}{c}\text { Corrected Com- } \\
\text { bined Issues }\end{array}$ & $\begin{array}{c}\text { Rejected Con- } \\
\text { tent Issues }\end{array}$ & $\begin{array}{c}\text { Rejected Exact } \\
\text { Duplication }\end{array}$ \\
\hline$(\mathrm{n}=5374)$ & $(\mathrm{n}=943)$ & $(\mathrm{n}=690)$ & $(\mathrm{n}=179)$ & $(\mathrm{n}=285)$ & $(\mathrm{n}=149)$ \\
\hline $70.5 \%$ & $12.4 \%$ & $9.1 \%$ & $2.3 \%$ & $3.7 \%$ & $2.0 \%$ \\
\hline
\end{tabular}

Table 1: Results from reviewing multiple choice questions (MCQs) for 23 pharmacy courses. Total number of MCQs = 7620.

\begin{tabular}{|l|c|c|c|c|c|}
\hline & \# Courses & \#Lectures & $\begin{array}{c}\text { Median Time (days) and } \\
\text { Interquartile (IQR) Range }\end{array}$ & $\begin{array}{c}\text { \% Timely MCQs } \\
\text { Submission* }\end{array}$ & p-value \\
\hline Overall & 13 & 437 & $13.0(7.0-28.0)$ & $77.8 \%$ & $<0.001$ \\
\hline Professional Year 1 & 4 & 261 & $18.0(9.0-30.5)$ & $83.9 \%$ & \\
\hline Professional Year 2 & 5 & 105 & $8.0(5.0-18.0)$ & $70.5 \%$ & \\
\hline Professional Year 3 & 4 & 71 & $11.0(6.0-39.0)$ & $66.2 \%$ & $80.6 \%$ \\
\hline Pharmaceutical Sciences & 3 & 211 & $17.0(7.0-31.0)$ & $75.2 \%$ & 0.18 \\
\hline Pharmacy Practice & 10 & 226 & $11.0(6.8-27.0)$ & 7 \\
\hline
\end{tabular}

Table 2: Time in days between receipt of MCQs and exam date and percent of timely submission of MCQs for 13 pharmacy courses taught in academic year 2015/2016, by professional year and department.

* Time in days between the receipt of MCQs and exam date $\geq 7$ days.

Of the faculty cancelled MCQs after they were attempted by students in the exam, a total of 132 exam MCQs were deleted (4.6\%) out of 2875 of a randomly selected MCQ of 30 pharmacy courses that were taught in 2016-2017. Sixteen courses had higher than the overall ( $>4.6 \%$ ) percentage of deleted exam MCQs and the other fourteen had less than overall percentage of deleted exam MCQs (Table 3). The range was 1 - 10\% deletion, with cognitive I (recall) MCQs topping the average percentage. The reasons for MCQ cancellations were documented by the course coordinator as, $65 \%$ confusing/difficult, 26\% low point-biserial correlation (psychometric analysis) and 9\% wrong question/other reasons (Figure 4). Five of the sixteen courses were listed below average in submitting correct MCQs, and in four of them the MCQ were consistently late.

\begin{tabular}{|l|c|c|}
\hline Cognitive Level & N & Percent \\
\hline Cognitive - Level I (recall) & 56 & $42.4 \%$ \\
\hline Cognitive - Level II & 47 & $35.6 \%$ \\
\hline Cognitive - Level III & 29 & $22.0 \%$ \\
\hline Total & 132 & $100.0 \%$ \\
\hline
\end{tabular}

Table 3: Distribution of cognitive level of deleted exam multiple choice questions (MCQs) for 30 pharmacy courses taught in 20162017. Total number of deleted MCQs $=132$.

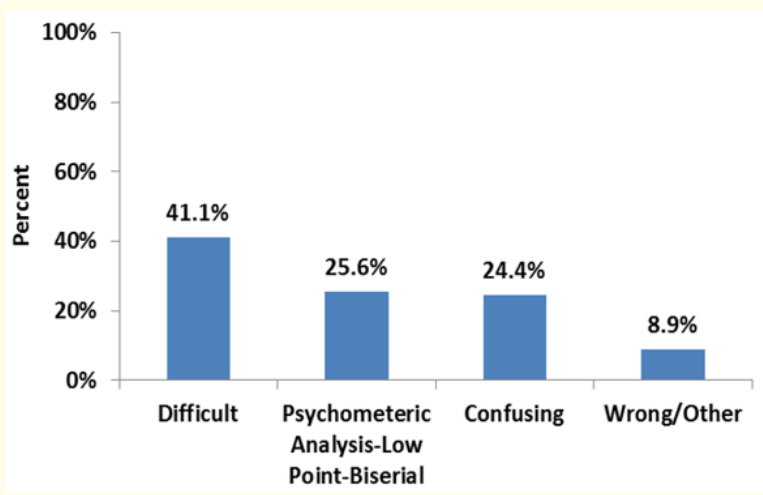

Figure 4: Reasons for deletion of exam multiple choice questions (MCQs) for 30 pharmacy courses taught in 2016-2017. Total number of deleted MCQs = 132 .

The student evaluation of courses for 2015-2016 is based on 24 questions that were classified under four domains: how well the course was prepared; the way it was conducted; the students overall evaluation of the course; and overall evaluations of all courses. Overall average $(95 \% \mathrm{CI})$ rating for all 43 courses given in academic year 2015/2016 was 3.63 (3.53, 3.73). Significantly higher average evaluation rating was observed in the Pharmaceutical Sciences department compared to Pharmacy Practice [average (95\% CI): 3.86 (3.64, 4.07) vs. 3.57 (3.45, 3.68); $\mathrm{p}=0.016$ ] (Figure 5). 


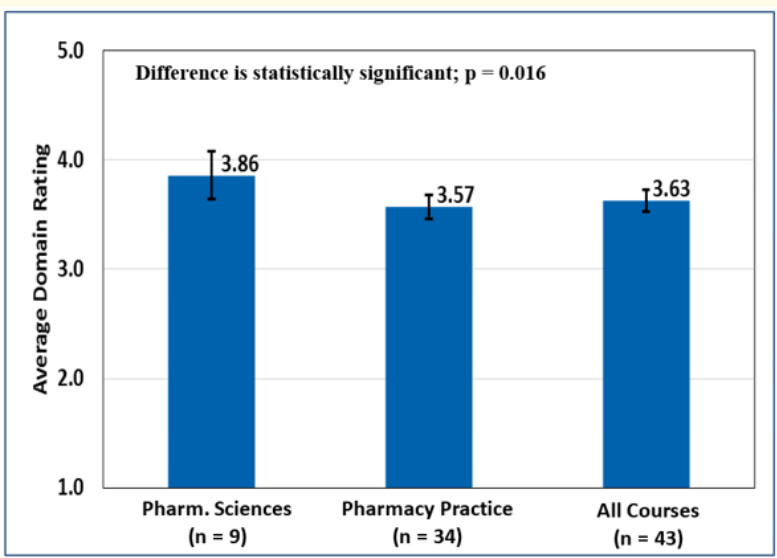

Figure 5: Average rating from course evaluation surveys in academic year 2015/2016, overall and by department. Total number of courses $=43$.

17 out of 43 courses had lower than average evaluation rating by male students (average $=3.63$ ).

Average evaluation rating was significantly different by professional year [average $(95 \% \mathrm{CI})$ for professional year 1 courses was $3.84(3.70,3.99)$ vs. $3.48(3.25,3.71)$ and $3.58(3.47,3.69)$ for courses in professional year 2 and 3 , respectively; $p=0.008$ ] (Figure 6).

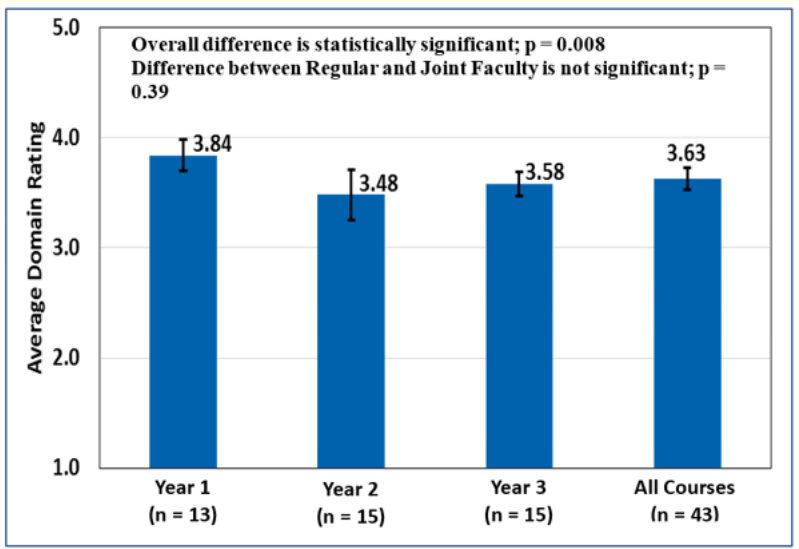

Figure 6: Average rating from course evaluation surveys in academic year 2015/2016, overall and by professional year. Total number of courses $=43$.

Results, overall and by professional year are displayed in figure 6 .

\section{Discussion}

An average of $70.5 \%$ of the 7620 reviewed MCQs for 23 courses passed the vetting (range 32.7\% - 97.8\%). The data we generated corroborates with the reported item writing flaws (IWF) in the literature that appears to be common in most academic institutes and colleges even in different board exams. In a review for CME MCQs in radiology journals, $43 \%$ of the items violated one standard of the adapted seven guidelines for writing [5]. Another project reviewed 3,509 MCQs, where $85 \%$ of the items were flawed, yet others reported $50 \%$ and $56.8 \%$ of flawed MCQs [6,7] and several studies reported violations of guidelines ranged between 46 - 76\% [8,9].

MCQs of Pharmacy practice courses in our college of pharmacy ranked below the Pharmaceutical sciences'. In the follow up investigations we documented late submission of pharmacy practice MCQs at $24.8 \%$. This compared to $19.4 \%$ of those in Pharmaceutical sciences. MCQ cancellation post exam administration of $4.6 \%$ were almost the same for Pharmacy Practice and pharmaceutical sciences, with MCQs of 16 out of 30 courses above that percentage. It has been reported in the literature that tests given to students without revision by examinations committee or by peer review could possess too many flawed questions [10]. This is clearly demonstrated in our findings. A study that assessed the performance of medical students in four examinations in an American medical school revealed that $46 \%$ of the revised MCQs contained IWFs and $10-15 \%$ of students who were considered as failures have been reclassified as passing the exam when flawed MCQs were removed $[2,3]$.

Student evaluation of courses was reviewed to explore if IWF had any effect. Eight pharmacy Practice courses were among the 12 courses that were ranked by students below average that year. There was no cause and effect evidence implicating the IWF in these courses.

All data pointed at the need for the college to tighten up its assessment practices in both divisions with a focused attention on Pharmacy Practice Courses taught by the joint faculty. The speculated causes for the generally weaker MCQs corroborate with what also was described in the literature $[7,11]$ : lack of enforcing the use of sound psychometric analysis; not having sufficient full time pharmacy practice faculty working alongside the joint faculty; limited assessment awareness of MCQ guidelines specifically among the joint faculty; limited available time for preparing MCQs 
per guidelines; failure of the college assessment unit to review the submitted MCQ prior to exam administration; lack of reviewing the consequences of flawed MCQ on the students with faculty. Many ideal item writing principles are in wide circulation and discussed in our workshops $[6,12]$. The most common types of errors and flaws that were documented in the literature included late and hurry submission of questions before the exam, ignorance and inexperience of MCQs writing criteria, implausible distractors, improper language and low cognitive level of questions [6,8,10,13-15]. The challenge to faculty increases when course learning outcomes requires higher cognitive levels in the crafted MCQs.

It is interesting to note that our College had, since its establishment six years ago, conducted yearly MCQ writing workshops. However, joint faculty were almost always absent due to their involvement in clinical practice at the hospital, whereas most pharmaceutical sciences faculty had better attendance resulting perhaps in enhanced performance in assessment. The joint faculty were notably committed to teaching and clinical services. Most are Pharmacy Board of Specialties certified, and most demonstrated reasonable achievements in practice and research. The placement of our fourth year students in the upper 25 - 35\% in the National pharmacy exams for admission to the national post graduate residency training programs is our anecdotal evidence to their teaching excellence.

Based on this project's findings, the College focused on mitigating the perceived weaknesses in MCQs through various interventions. It also implemented a strategic plan to increase college based clinical faculty educated in North America through the state supported scholarship program to fill the shortage gap [16]. The two initiatives was thought to improve our assessment processes and outcome overtime.

Our objective of expanding this project was to attempt to identify a cause and effect that would then facilitate an efficient intervention. For example, it was quite notable that three of the six Therapeutics courses, the backbone of the Pharmacy Practice Program, fell below the average in IWF; two had up to $80 \%$ level 1 recall MCQs contrary to the expectations in clinical courses. Of them, one had late submission of MCQ up to $21 \%$ of the time. Students evaluated these three courses 3.24 - 3.62/5, an unfavorable 65\% - 72\%. It is conceivable that the poorly crafted MCQs pertaining to these courses, their low level of cognition through the hurried submission, and perhaps the manner these lectures are delivered, reflect- ed negatively on the students' evaluation. In an effort to see if that affected the rate of student absenteeism, we discovered contrary to our expectations that these courses had less than the average absenteeism for that particular year (5\% - 9\%) while the overall average of absence for that year was 10\% (range 1\% - 28\%).

Pharmaceutical Sciences courses fared better presumably because their faculty were college based full time faculty as opposed to their counterparts in pharmacy practice. They had far more teaching experience than their counterparts and were the sole instructors of most of their respective courses contrary to Pharmacy practice courses.

There were three key findings in our study. First, overall, pharmacy practice courses had significantly lower percentage of MCQs that passed the review compared to pharmaceutical sciences courses. Also, courses taught by joint faculty (hospital based part time faculty) had significantly lower percentage of MCQs passing the review compared to those courses taught by regular faculty. This result may be related to the notably higher number of instructors for courses taught by joint appointed faculty, which was clearly demonstrated by the negative and significant correlation between number of instructors and the declining quality of MCQs for courses (Figures 2 and 3). Other contributors to this finding could be the limited time the joint appointed clinical faculty allocates to prepare for course teaching and assessment due to their main responsibilities in busy clinical settings. Previous studies have reported that clinical instructors were less likely to have adequate time to write MCQs, thus resulting in issues related to IWFs [17]. It is worth noting that the sequential model of teaching is used in our college, where some courses are taught by multiple instructors but only one instructor is present at a time. This is substantially different than other teaching models such as team teaching, where all instructors are present for all classes and thus share the lead role; and hybrid teaching where all instructors are present sometimes and one instructor is present at other times. A previous survey study on the benefits and drawbacks of using multiple instructors in a large research university in Canada suggested that advantages are maximized and disadvantages minimized either in courses with two or more instructors interacting and collaborating in class or when special care is taken with coordination and collaboration if the course is sequentially taught [18]. Our findings demonstrated that increased number instructors teaching any given course was also associated with higher rate of IWF (Figure 1-3). Additional 
analysis demonstrated worse student performance in courses taught by 6 or more instructors [average (SD) grade out of 100 was 82.2 (1.0) vs. 84.0 (1.4) for courses taught by fewer instructors; $p$ $=0.033]$. These results compel us to reduce the number instructors in single courses. An alternative approach would be to design and enforce strategies to increase collaboration and coordination between multiple instructors in terms of unification of teaching styles and assessment in addition to methods of communication with students.

The cause and effect between poorly written MCQs and their late submission could not be proven and remains speculative.

Our study has a number of limitations. The review may have focused more on the use of appropriate language in MCQs than other flaw criteria. Furthermore, our review faculty, who were mostly PhD holders, may not all have the mastery of IWF detection as should be. A strength of this study is its use of a large database of MCQs. Another important outcome of this study was its value in terms of assessing the level of MCQs correctness by number and type of teaching faculty.

\section{Conclusion}

It appears from the outcome of this project that for any MCQ assessment in clinical programs to succeed, pharmacy faculty, especially joint practice ones, need to go through the MCQ writing skills workshops available in almost all large institutions. It is crucial to extract from all faculty the commitment to adhere to the established MCQ writing guidelines. The firm enforcement of psychometric analysis standards is also helpful in guiding the assessment process but is not more important than the final judgment of the material expert faculty. Course coordinators and support faculty need to review all submitted MCQs prior to their administration to students, and all violations must be discussed with the authoring faculty. Deleted questions must also be discussed with the students to solidify their knowledge base in relation to the disputed MCQs. It is highly advisable that each course coordinator meet with all course teaching faculty in advance of the course commencement to discuss approach, teaching effectiveness, and assessment guidelines even the compliance with the cognition level for the expected MCQ per course learning outcomes. Finally, the most qualified teaching faculty in both departments are the specialists in their fields whether it is in pharmaceutical sciences or pharmacy practice. Thus, refraining from assigning non-specialists or numerous faculty to teach any given course, regardless how easy the course may appear, and changing the teaching faculty assignments frequently appear to be counterproductive to student comprehension and the assessment program.

While we may have documented some shortcomings in the assessment program due to having joint faculty solely teaching all clinical courses, we strongly believe that the recruitment of full time Pharmacy practice faculty create a more cooperative culture between the two types of faculty that leads to better cooperation in complete compliance with MCQ writing guidelines and in teaching effectiveness. The preliminary appointment of two such full time faculty in our college along with our improvement processes has clearly demonstrated the correctness of our speculations on some of the issues that needed resolution.

\section{Bibliography}

1. Pate Adam and David J Caldwell. "Effects of Multiple-Choice Item-Writing Guideline Utilization on Item and Student Performance". Currents in Pharmacy Teaching and Learning 6.1 (2014): 130-134.

2. Steven M Downing. "The Effects of Violating Standard Item Writing Principles on Tests and Students: The Consequences of Using Flawed Test Items on Achievement Examinations in Medical Education". Advances in Health Sciences Education 10.2 (2005): 133-143.

3. Downing SM. "Construct-Irrelevant Variance and Flawed Test Questions: Do Multiple-Choice Item-Writing Principles Make Any Difference?" Acadamic Medicine 77.10 (2002): S103-104.

4. Marie Tarrant and James Ware. "Impact of Item-Writing Flaws in Multiple-Choice Questions on Student Achievement in HighStakes Nursing Assessments". Medical Education 42.2 (2008): 198-206.

5. DiSantis D J., et al. "Journal Club: Prevalence of Flawed Multiple-Choice Questions in Continuing Medical Education Activities of Major Radiology Journals". AJR American Journal of Roentgenology 204.4 (2015): 698-702.

6. Nedeau-Cayo R., et al. "Assessment of Item-Writing Flaws in Multiple-Choice Questions". Journal for Nurses in Professional Development 29.2 (2013): 52-57; quiz E1-2.

7. Pais J., et al. "Do Item-Writing Flaws Reduce Examinations Psychometric Quality?" BMC Research Notes 9 (2016).

8. Tarrant M., et al. "The Frequency of Item Writing Flaws in Multiple-Choice Questions Used in High Stakes Nursing Assessments". Nurse Education in Practice 6.6 (2006): 354-363. 
9. Masters JC., et al. "Assessment of Multiple-Choice Questions in Selected Test Banks Accompanying Text Books Used in Nursing Education". Journal of Nursing Education 40.1 (2001): 2532.

10. Tarrant M and J Ware. "A Framework for Improving the Quality of Multiple-Choice Assessments". Nurse Education 37.3 (2012): 98-104.

11. Vyas R., and A. Supe. "Multiple Choice Questions: A Literature Review on the Optimal Number of Options". The National Medical Journal of India 21.3 (2008): 130-133.

12. Gopalakrishnan S and P M Udayshankar. "Question Vetting: The Process to Ensure Quality in Assessment of Medical Students". Journal of Clinical and Diagnostic Research 8.9 (2014): XM01-XM03.

13. Clifton Sandra L and Cheryl L Schriner. "Assessing the Quality of Multiple-Choice Test Items". Nurse Education 35.1 (2010): 12-16.

14. Abdulghani H M., et al. "Faculty Development Programs Improve the Quality of Multiple Choice Questions Items' Writing". Scientific Report 5 (2015): 9556.

15. Sanders S. "Assisting Nursing Students through Linguistic Modification of Multiple Choice Questions". 42nd Biennial Convention Kaplan Nursing (2013).

16. Albekairy Abdulkareem M., et al. "Strategic Initiatives to Maintain Pharmaceutical Care and Clinical Pharmacists Sufficiency in Saudi Arabia". SAGE Open Medicine 3 (2015): 2050312115594816.

17. Craddock Esther. "Developing the Facilitator Role in the Clinical Area”. Nurse Education Today 13.3 (1993): 217-224.

18. Jones Francis and Sara Harris. "Benefits and Drawbacks of Using Multiple Instructors to Teach Single Courses". College Teaching 60.4 (2012): 132-139.

\section{Assets from publication with us}

- Prompt Acknowledgement after receiving the article

- Thorough Double blinded peer review

- Rapid Publication

- Issue of Publication Certificate

- High visibility of your Published work

Website: www.actascientific.com/

Submit Article: www.actascientific.com/submission.php

Email us: editor@actascientific.com

Contact us: +919182824667 